\title{
Significance of antiplatelet therapy in emergency myocardial infarction treatment
}

\author{
Anna Komosa, Maciej Lesiak, Andrzej Siniawski, Tatiana Mularek-Kubzdela, Stefan Grajek \\ $1^{\text {st }}$ Department of Cardiology, Poznan University of Medical Sciences, Poznan, Poland
}

Postep Kardiol Inter 2014; 10, 1 (35): 32-39

DOI: $10.5114 /$ pwki.2014.41466

\begin{abstract}
A bstract
Antiplatelet drugs play a crucial role in the treatment of patients with myocardial infarction, particularly in association with percutaneous coronary intervention. Their main advantage is the reduction of adverse ischemic incidents and the major disadvantage is the increase in the frequency of hemorrhages. Thus, the choice of appropriate drug depends on the right risk assessment of the development of these complications in individual patients. The aim of this article is to provide an update of antiplatelet therapy in emergency myocardial infarction treatment. Currently, the most important role in the process of platelet inhibition is played by ADP P2Y12 blockers: clopidogrel, prasugrel and ticagrelor. Clopidogrel and prasugrel belong to thienopyridines, and ticagrelor, a drug of irreversible action, is an analogue of adenosine triphosphate. By 2011 clopidogrel, alongside aspirin, had the highest recommendations of world cardiology associations for acute coronary syndrome treatment. The position on clopidogrel was changed following the publication of European Society of Cardiology guidelines for STEMI in 2012 which advocate the administration of acetylsalicylic acid (ASA) and ADP receptor blocker (in combination with ASA). It needs to be stressed that prasugrel and ticagrelor received class IB recommendation, while clopidogrel received only IC. However, the most recent studies aimed at introducing a new generation of antiplatelet drugs of high efficacy in prevention of ischemic incidents and of reversible action: cangrelor and elinogrel, which raise hopes for better prognosis for myocardial infarction patients.
\end{abstract}

Key words: antiplatelet therapy, platelets, P2Y12, myocardial infarction, angioplasty.

\section{Introduction}

Myocardial infarction usually results from sudden occlusion of one of the coronary arteries caused by the damage of unstable atherosclerotic plaque (UAP). The plaque damage activates coagulation processes and the resulting thrombus closes the vessel. Primary coronary angioplasty is currently viewed as the most effective treatment for myocardial infarction; however, stenting of infarct-related artery (IRA) may lead to stent thrombosis and as a result to another infarction. The risk of early stent thrombosis in myocardial infarction patients with ST segment elevation (STEMI) is significantly higher than in elective surgery (3\% vs. $0.3-0.4 \%$ respectively) [1]. Due to the fact that platelet activation plays a key role in this process, appropriate antiaggregation therapy is crucial.

\section{The role of platelets in thrombosis in myocardial infarction}

Platelet activation is performed in a specific and nonspecific manner. Specific activation is related to direct activation of platelets by substances released as a consequence of atherosclerotic plaque rupture. Non-specific platelet activation for aggregation is stimulated by hemodynamic disturbances leading to a decrease of the shear rate. A low shear rate results from the disturbed and non-effective blood flow in the vessel which activates platelets (decreased flow and/or turbulent flow).

The most commonly used antiplatelet drugs include GPIIb/IIla glycoprotein receptor blockers (abciximab, tirofiban, eptifibatide), acetylsalicylic acid (ASA) and ADP P2Y12 receptor blockers, such as clopidogrel, prasugrel and ticagrelor. Platelet activation requires the release of stimulating substances, such as thrombin, thromboxane $A 2$ and ADP. The combination of ADP and receptor P2Y12 activates glycoprotein receptors $\mathrm{Ilb} / \mathrm{Ill}$ a resulting in platelet degranulation, thromboxane production and their subsequent aggregation and binding with fibrinogen. Inhibitors of GP IIb/IIla hinder this process, allowing for infarct vessel patency even in the pre-operative period in approximately $1 / 3$ of patients. It has been proved that

\section{Corresponding author:}

Anna Komosa MD, PhD, $1^{\text {st }}$ Department of Cardiology, Poznan University of Medical Sciences, 1/2 Długa St, 60-848 Poznan, Poland, phone: +48 6185491 46, fax: +48 6185490 85, e-mail: komosa.ania@gmail.com

Received: 24.09.2013, accepted: 9.01.2014. 
pre-surgical combined treatment with ASA (250 mg i.v.), unfractionated heparin (5000 U i.v.) and Ilb/llla blocker statistically significantly decreases 2-year mortality in STEMI by $6 \%$ [2]. It was observed that early administration of GP IIb/IIla blockers also improved the coronary flow evaluated on the basis of the TIMI scale, as well as early treatment results in STEMI myocardial infarction patients in APEX-AMI examination [3]. Metaanalysis evaluating the application of Ilb/Illa blockers in STEMI showed their significant effectiveness in high-risk myocardial infarction patients (e.g. large necrosis, left ventricular dilation) [4]. The recently published INFUSE AMI study showed that abciximab administered locally into the developed thrombus using a special infusion catheter significantly decreased the range of infarction assessed by MRI [5].

Currently the most important role in the process of platelet inhibition is played by ADP P2Y12 blockers. This group includes, among others, thienopyridines. The first one used in the treatment of acute coronary syndrome (ACS) was ticlopidine. Due to its numerous side effects it has been almost entirely superseded by clopidogrel.

Clopidogrel and prasugrel also belong to thienopyridines. Drugs from this group irreversibly modify the structure of the ADP platelet receptor P2Y12, directly and specifically blocking ADP access, and inhibit GP IIb/IIla complex activation. The third drug of a similar nature, but not a thienopyridine and exhibiting irreversible action, is ticagrelor.

\section{Clopidogrel}

Clopidogrel is a thienopyridine derivative of the second generation. The speed and degree to which the drug is absorbed (bioavailability) from its pharmacological form exceeds $50 \%$. Clopidogrel binds to plasma proteins and tissues in $94-98 \%$ and its half-life is $7-8 \mathrm{~h}$. The drug irreversibly modifies the structure of $\mathrm{P} 2 \mathrm{Y} 12$ platelet receptor by directly and specifically inhibiting the activation of GP IIb/IIla complex. Its washout period remains throughout platelet lifetime (7-10 days). Only 60-70\% of receptors exhibit sensitivity to clopidogrel and thus a standard dose does not lead to complete inhibition of all receptors, enabling about half of the thrombocytes to retain their aggregation activity. Efficacy of the drug depends not only on the dose but also on the time of therapy onset. The maximum antiplatelet effect is obtained within approx. 2-3 $\mathrm{h}$ after administration of a single loading dose of $600 \mathrm{mg}$ and within approx. 3-7 days after application of $75 \mathrm{mg} /$ day. Normal platelet functions are restored 5-7 days following drug discontinuation and are related to the restoration of a number of circulating cells [6]. The possible necessity to perform cardiac surgery definitely points to the drug's shortcoming. On the other hand, this may act as a protection against the consequences of omissions of even a few doses of the drug. In order to avoid the risk of significant bleeding elective surgery (e.g. direct myocardial revascularization) should be performed within 5-7 days after the last dose of clopidogrel has been administered [7].

Clopidogrel is a prodrug, which in the stage of intestinal absorption undergoes hydrolysis to an intermediate metabolite - an ester by P-glycoprotein (ABCB1). This is followed by a two-phase process of hepatic oxidation with cytochrome (CYP) 450. Clopidogrel exhibits a thiol group conditioning its antiaggregation activity only in the second phase of oxidation. The most desired result of metabolism is the active form of drug inhibiting platelet aggregation, which constitutes only $15 \%$ of the drug. The remaining part (85\%) is a non-active derivative of carbonic acid. The drug is eliminated by renal (50\%) and fecal (46\%) pathways [8].

Several studies have proved the effectiveness of clopidogrel. The CURE study analyzed a group of $12,562 \mathrm{pa}-$ tients with unstable angina pectoris or myocardial infarction without ST-segment elevation who were treated with clopidogrel - loading dose $300 \mathrm{mg}$ and maintenance dose $75 \mathrm{mg}$ daily combined with aspirin administration for 3 to 12 months. The result was a 20\% decrease in risk of cardiovascular death, $\mathrm{MI}$, and brain stroke in comparison with the patients treated only with aspirin [9]. A positive result of the therapy related mostly to the patients shortly after myocardial infarction without ST-segment elevation, interventionally treated (PCl-CURE study), which showed a 31\% decrease in the frequency of cardiovascular death, $\mathrm{MI}$, and brain stroke as compared to the group treated only with aspirin and placebo [10].

Also the COMMIT-CCS-2 study performed on a large group of patients (45,852 patients) with myocardial infarction and ST-segment elevation showed a lower risk of death, secondary myocardial infarction or brain stroke when treated with $75 \mathrm{mg}$ clopidogrel and aspirin $(22,961$ patients) as compared to placebo and aspirin $(22,891$ patients). Four-week observation showed a proportional reduction in death rate, myocardial infarction and brain stroke $(9.2 \%$ in clopidogrel group vs. $10.1 \%$ for placebo, $p=0.002$ ). No statistically significant differences were found between the studied groups as for the side effects in terms of ischemic episodes requiring blood transfusion and intracranial bleeding (0.58\% vs. $0.55 \%, p=0.59)$ [11].

The CLARITY-TIMI 28 study, published in 2006, included 3491 STEMI myocardial infarction patients treated fibrinolytically who, apart from ASA and heparin, were administered either clopidogrel or placebo no longer than for the first 8 days. Administration of clopidogrel reduced by $21 \%$ the frequency of ischemic events: death, myocardial infarction or the need for another revascularization. This study showed that by adding clopidogrel to a standard fibrinolytic therapy the occurrence of the composite endpoint of death, myocardial infarction, and no patency of infarct-related artery after fibrinolytic therapy is reduced by $36 \%$ [12]. 
There have been numerous papers proving that an increase of a loading dose of clopidogrel specifically improves the antiaggregation result; the PERPAIR study focused on the dose change from $150 \mathrm{mg}$ to $300 \mathrm{mg}$ [13], and the ISAR-CHOICE study on the dose change from $300 \mathrm{mg}$ to $600 \mathrm{mg}$. However, there was no evidence to support the increase of a loading dose to $900 \mathrm{mg}$, probably due to the fact that the maximal active drug form has been achieved [14]. The CLEAR-PLATELET study showed that administration of clopidogrel in a loading dose of $600 \mathrm{mg}$ was related to an improved pharmacodynamic result when compared to a $300 \mathrm{mg}$ dose [15].

The effects of an increased loading dose of clopidogrel (600 mg) were assessed in patients with acute coronary syndromes in the CURRENT-OASIS 7 study. It included over 17,000 patients with ACS and compared two manners of clopidogrel administration. The first one analyzed the administration of a loading dose of $600 \mathrm{mg}$, followed by 1-week administration of $150 \mathrm{mg}$ and then $75 \mathrm{mg}$ daily. The second, standard treatment, was related to the administration of a lower loading dose: $300 \mathrm{mg}$, followed by $75 \mathrm{mg}$ administration for 30 days. This study also compared the administration of a higher loading dose of aspirin (300-325 mg) and a maintenance dose of 75-100 $\mathrm{mg}$ daily. It was proved that, contrary to the group treated with a standard dose of clopidogrel, the percutaneous coronary intervention ( $\mathrm{PCl}$ )-treated group when administered a double dose of clopidogrel showed a reduction in primary endpoint ( $3.9 \%$ vs. $4.5 \%, p=0.039$ ) and reduction in stent thrombosis occurrence $(0.7 \%$ vs. $1.3 \%$, $p=0.0001$ ). However, the administration of a lower or higher dose of aspirin was noted to be of no significance. Extensive ischemia was found to be more frequent after the administration of a double clopidogrel dose (1.6\% vs. $1.1 \%, p=0.009)$. No significant differences were found in relation to the dose of ASA ( $1.5 \%$ vs. $1.3 \%, p=0.20)$ [16]. A significant problem relating to antiaggregation treatment is the increased risk of hemorrhagic complications. The CHARISMA study showed that the administration of double therapy, composed of aspirin and clopidogrel at daily doses of 75-162 and $75 \mathrm{mg}$ respectively, significantly increases the risk of ischemic events in the period of approx. 250 days after the therapy onset [17].

By 2011 clopidogrel, alongside aspirin, had the highest recommendations of world cardiology associations (ESC/ACC/AHA) for ACS treatment. The position on clopidogrel was changed following the publication of the ESC (European Society of Cardiology) guidelines for STEMI in 2012, which advocate the administration of ASA and ADP receptor blocker (in combination with ASA): a) prasugrel - patients of age $<75$, not taking clopidogrel before, who have not undergone a brain stroke or transient cerebral ischemia, b) ticagrelor, c) clopidogrel, if prasugrel and ticagrelor are unavailable or contraindicated [18]. It needs to be stressed that prasugrel and ticagrelor received a class IB recommendation, while clopidogrel received only IC. The administration of antiaggravation drugs should be commenced as soon as possible before coronarography. It is admissible to administer a loading dose of ticagrelor to patients taking clopidogrel. In January 2013 "Circulation" published the latest guidelines of American associations (American College of Cardiology Foundation/American Heart Association) for STEMI, according to which clopidogrel, similarly to prasugrel and ticagrelor, received a class IB recommendation. Chronically, antiaggregation therapy with $\mathrm{P} 2 \mathrm{Y} 12$ receptor inhibitors should be continued for 12 months at maintenance doses in the following manner: clopidogrel $75 \mathrm{mg}$, ticagrelor $90 \mathrm{mg}$ (twice daily) or prasugrel $10 \mathrm{mg}$ [19].

\section{Low responsiveness to clopidogrel}

Current available data show that $5-45 \%$ of patients display resistance to clopidogrel [20]. Low responsiveness to clopidogrel is caused by multiple factors such as the lack of appropriate cooperation between a patient and a doctor and premature drug discontinuation, individual differences in intestinal drug absorption (especially in obese, elderly and diabetic patients), the immunological state of a patient (injections), or, finally, interactions with other drugs (e.g. proton pump inhibitors). Specific factors include individual genetic conditioning affecting the velocity of drug transformation at several stages: oxidation by cytochrome (CYP) 450 enzymes (cytochrome genetic polymorphism), thrombin receptor activation (PAR-1) [21] and the presence of other enzymes participating in the process of clopidogrel bioactivation (PON-1) [22].

In 2010 Bonello et al. published the definition of resistance to clopidogrel [23], which was based on the absolute value of platelet reactivity cutoff during antiaggregation therapy for the commonly applied methods of platelet aggregation inhibition measurement. The term high on-treatment platelet reactivity (HTPR) was introduced, i.e. increased platelet reactivity despite antiaggregation treatment. Many papers have proved a significant influence of HTPR on adverse clinical incidents. The study by Breet et al. published in 2010 conducted on a group of 1069 elective $\mathrm{PCl}$ patients showed a marked increase in ischemic events during 1-year observation in patients with high platelet activity (HR: 2.0) [24]. Similarly, Sibbing et al. reported significantly more frequent stent thrombosis in a group of $1608 \mathrm{PCl}$ patients with antiproliferative drug-eluting stents who were found to have increased platelet reactivity during clopidogrel treatment in a 30 day observation period (OR: 9.4) [25].

\section{Clopidogrel metabolism}

As mentioned before, clopidogrel is bioactivated in a two-step hepatic oxidation process, mainly by hepatic enzymes: CYP1A2, CYP3A4, CYP2B6 and CYP2C19 [26]. Mutations related to the allele coding the development 
of these enzymes are responsible for lower responsiveness to clopidogrel. The patients who are carriers of such mutations are particularly prone to stent thrombosis, myocardial infarction or death. Genetic diversity of cytochrome (CYP) 450 enzymes is responsible for about $80 \%$ of incidents related to platelet aggregation disturbances [27]. Among several cytochrome (CYP) 450 enzymes CYP2C19 plays a particularly crucial role in the process of clopidogrel activation. There are 25 polymorphic varieties of CYP2C19, among which CYP2C19*2 and ${ }^{*} 3$ are associated with impaired development of the active metabolite and, as a result, with decreased platelet inhibition. The healthy carriers of CYP2C19*2 allele showed decreased concentration of clopidogrel active metabolite in blood (by 34\%) and lower aggregation inhibition as compared to the noncarriers, who did not have this allele mutation [28]. A recently published meta-analysis of 10 studies, by Hullot et al., proved that CYP2C19 allele carriers are $30 \%$ more likely to develop major adverse cardiac incidents (MACE) as compared to noncarriers (9.7\% vs. $7.8 \%$; OR: $1.29, p<0.001)$ [29].

\section{Significance of genetic tests}

There are many doubts relating to genetic tests used for detection of patients who are carriers of genes responsible for the impaired metabolism of antiaggregation drugs. It is estimated that as many as $30 \%$ of the white population are carriers of this defective gene variation, which results in an increased risk of adverse cardiovascular incidents. Despite the fact that it is theoretically possible to detect genetic variations predisposing to impaired response to antiaggregation therapy, so far there have been no available unequivocal data establishing how "genetic resistance" relates to clinical events in patients. Wide-scale implementation of genetic examinations with the aim of defining a variety of responses to antiplatelet drugs, in particular to clopidogrel, still remains a controversial issue. Ticagrelor is absorbed as an active substance, and genetic factors are not important for its activity [30]. Prasugrel, although it undergoes cytochrome transformation, depends on it to a lesser extent and the evaluation of its genetic distinctiveness also appears to be unnecessary here [31].

The Food and Drug Administration (FDA) in the United States has advocated including a warning in clopidogrel leaflets about its possible incomplete efficacy. Moreover, patients are informed about the possibility to have genetic tests performed at bedside, which may be helpful when choosing the appropriate drug and dose. Bedsides, genetic assessment may be useful for the treatment of STEMI patients. Currently available scientific data suggest that the authors who urge these tests to be implemented and propagated are right about perceiving them as a chance to improve the results of emergency myocardial infarction treatment [32]. However, genetic test op- ponents point out that there is a lack of sufficient data of genetic conditioning responsible for clopidogrel metabolism as well as studies related to the influence of genes on treatment efficacy [33]. A Canadian study from 2010 performed on a group of 5059 acute coronary syndrome patients showed that antiaggregation efficacy of clopidogrel in the examined persons was not related to CYP2C19 genotype [34]. Thus, it seems necessary to perform further research and learn more about the factors responsible for lower responsiveness to clopidogrel. In 2011 the results of a meta-analysis of 32 major studies were published, which analyzed the effects of CYP2C19 polymorphism on platelet inhibition degree and clinical incidents in over 42,000 patients. It was shown that a lower level of active clopidogrel metabolite and increased platelet activity were present despite antiaggregation treatment in carriers of an allele of impaired clopidogrel metabolism. Despite the compelling number of included patients, no major influence of genotype on adverse coronary-vascular incidents was found [35]. So far it has been established that the consequences of genetic polymorphism, responsible for varied activity and thus for clinical efficacy of clopidogrel, are inconclusive and therefore further studies need to be conducted.

Another postulated mechanism of decreased sensitivity to clopidogrel is polymorphism of paraoxonase-1 (PON-1) responsible for clopidogrel bioactivation. Recent reviews have proved polymorphism Q192R of PON-1 to be a major determinant of clopidogrel activation [36]. The prospective research conducted on 1982 patients showed that homozygotes QQ192 responsible for PON-1 deficit caused statistically significantly lower clopidogrel activity. In order to conclusively define the influence of PON-1 on clopidogrel metabolism further studies are required [37].

\section{Prasugrel}

Prasugrel differs from clopidogrel in that it is activated in a single step in the liver. Active metabolite develops faster and thus more promptly reaches a higher concentration in the blood, which to a greater extent affects its speed and efficacy of action. Individual diversity of patients' sensitivity to prasugrel appears to be of no relevance. The TRITON-TIMI 38 study showed that the administration of prasugrel to ACS patients, including in those with ST-segment elevation, when compared with clopidogrel, is associated with a significant reduction in the primary endpoint - death due to cardiovascular reasons, myocardial infarction or brain stroke. It needs to be stressed here that prasugrel treatment showed greater efficacy in 30-day and 15-month period observations only in patients with anterior wall myocardial infarction: $9.5 \%$ vs. $6.5 \%, p=0.017$ and $12.4 \%$ vs. $10.0 \%$, $p=0.0221$ respectively. However, the subgroup including myocardial infarction patients treated with primary $\mathrm{PCl}(n=2438 / 69 \%)$ showed no statistically significant 
differences relating to the frequency of primary endpoint occurrence between clopidogrel and prasugrel treatment both in 30-day and 15-month period observations: $8.2 \%$ vs. $6.6 \%$; HR: 0.80 (95\% Cl: $0.60-1.08), p=$ 0.144 and $11.6 \%$ vs. $10.2 \%$, HR: 0.87 (95\% Cl: $0.68-1.11$ ), $p=0.2662$ respectively. These two subgroups also did not differ in terms of frequency of serious hemorrhagic events (according to TIMI). However, the brain stroke patients (3.8\%) treated with prasugrel significantly more often showed intracranial hemorrhage $(2.3 \%$ vs. $0.0 \%$, $p=0.02)$. On the basis of the TRITON-TIMI 38 study a group of patients particularly prone to hemorrhagic complications was distinguished: patients who underwent brain stroke or temporary cerebral ischemia, patients over 75 years of age and with body weight below $60 \mathrm{~kg}$ [38]. The TRILOGY study which was published in October 2012 and focused on about 10,000 patients with myocardial infarction without ST-segment elevation treated conservatively did not confirm the advantage of prasugrel over clopidogrel in relation to occurrence of ischemic complications. A significant reduction in cardiovascular deaths - myocardial infarction and brain stroke - connected with prasugrel administration was observed in the group of patients below 75 years of age, in whom the conservative treatment was commenced after the performance of angiography tests (HR: 0.85; 95\% Cl: 0.72-1.00; $p=0.04$ ). This study was conducted on a very large population of patients and proved the administration of maintenance prasugrel dose to be safe in patients who were initially treated with clopidogrel. Also, the reduced maintenance dose of prasugrel ( $5 \mathrm{mg}$ ) was found to be safe in patients aged > 75 with body weight below $60 \mathrm{~kg}$ - this group showed no increased risk of hemorrhagic complications [39]. Also in 2012 the results of the TRIPLET study were published, which tested the influence of antiaggregation drug change from clopidogrel to prasugrel on platelet aggregation inhibition and the occurrence of adverse clinical incidents. The study included 282 patients with acute coronary syndrome, who were randomized into 3 groups and who received respectively: 1) placebo loading dose followed by $60 \mathrm{mg}$ prasugrel, 2) $600 \mathrm{mg}$ clopidogrel followed by $60 \mathrm{mg}$ prasugrel, 3) $600 \mathrm{mg}$ clopidogrel followed by $30 \mathrm{mg}$ prasugrel. No significant differences relating to platelet aggregation inhibition were noted with the use of the VerifyNow system in patients treated with prasugrel, irrespective of the previously administered clopidogrel loading dose. In the first and in the second group 3 cases of hemorrhagic complications were found while in the third group 6 such cases were observed, i.e. in patients treated with $600 \mathrm{mg}$ clopidogrel loading dose followed by $30 \mathrm{mg}$ prasugrel [40].

\section{Ticagrelor}

Ticagrelor is an analog of adenosine triphosphate that, unlike clopidogrel and prasugrel, is not a prodrug.
Thus, after administration it does not require metabolic activation by cytochrome (CYP) 450 - the issues of hepatic passage and interactions with other drugs are eliminated. The drug blocks platelet $\mathrm{P} 2 \mathrm{Y} 12$ receptor reversibly and its half-life is about $12 \mathrm{~h}$. Its short period of action gives ticagrelor a potential advantage over thienopyridines in patients qualified for cardiac surgery. DISPERSE2, a comparative study of ticagrelor and clopidogrel, revealed no differences related to frequency of hemorrhagic complications [41]. Ticagrelor, when compared to clopidogrel, is characterized by reaching faster a potent concentration in serum (1.5-3 h) and low individual response diversities, and also faster platelet aggregation inhibition $(2 \mathrm{~h}$ ). The ONSET/OFFSET study performed on a group of 123 patients with stable coronary artery disease showed markedly faster and stronger platelet inhibition due to ticagrelor administration as compared to clopidogrel $(600 \mathrm{mg}$ followed by $75 \mathrm{mg}$ within a day). Also, after discontinuation of ticagrelor platelets resumed their normal activity sooner than in the case of clopidogrel [42]. The PLATO study which randomized 18,624 patients with ACS, including 3203 patients who were primary $\mathrm{PCI}$ treated (STEMI PLATO), comparatively analyzed clopidogrel and ticagrelor. Clopidogrel was administered in a loading dose of $300 \mathrm{mg}$ and maintenance dose of $75 \mathrm{mg}$ while ticagrelor was administered in doses of 180 and $90 \mathrm{mg}$ respectively at the onset of surgery. The study conducted on the STEMI PLATO subgroup, after 12 months, showed a significantly reduced risk of endpoints (deaths due to cardiovascular events, myocardial infarction or stroke) in patients treated with ticagrelor as compared to clopidogrel ( $11 \%$ vs. $9.3 \%, p=0.02$ respectively). The main reason for this difference was a decreased frequency of myocardial infarction occurrence (6.1\% vs. $4.7 \%, p=0.01)$. Also, a specific absolute reduction by $1.4 \%$ in the total number of deaths was found. No significant increase in the risk of serious hemorrhagic complications was observed according to the criteria applied by the authors ( $4.9 \%$ vs. $4.5 \%, p=N S$ ), or according to TIMI (6.4\% vs. $6.0 \%, p=$ NS) [43].

As proved in the currently available studies, the frequency of complications in the form of major bleeding according to the TIMI definition (Thrombolysis in Myocardial Infarction) varied and was $0.6 \%$ in COMMIT and $11.2 \%$ in PLATO. A significant percentage of hemorrhagic incidents found in the PLATO study, in the clopidogrel group, was observed in the subgroup treated with direct myocardial revascularization [44]. However, the group of patients treated with ticagrelor, who did not undergo CABG, was found to have statistically more major bleeding events when compared to the standard clopidogrel dose $(2.8 \%$ vs. $2.2 \%, p=0.03)$. The risk of brain stroke was low in both groups, yet greater in the ticagrelor treated group: $1.7 \%$ vs. $1.0 \%$; HR: 1.63 (95\% Cl: 1.7-2.48, $p=0.02)$. In the last PLATO analysis conducted on 1152 
(6\%) patients who experienced brain stroke and transient cerebral ischemia, the frequency of bleeding in ticagrelor/clopidogrel groups showed no statistically significant difference: $14.6 \%$ vs. $14.9 \%$, HR: 0.99 (95\% Cl: 0.71-1.37) [45]. Also, no major differences were observed relating to intracranial bleeding incidents (4.0 vs. 4.0) [46].

Due to the greater efficacy of prasugrel and ticagrelor in cardiovascular incidents prevention, a number of experts from the Polish Cardiac Society suggested a new model of antiplatelet therapy in STEMI (Model B), i.e. introduction of prasugrel or ticagrelor in the place of clopidogrel. This model is based on replacing a loading dose of clopidogrel (600 mg) administered pre-hospitally or on admission to the hemodynamic laboratory with the new antiplatelet drugs: prasugrel (loading dose $60 \mathrm{mg}$ ) or ticagrelor (loading dose $180 \mathrm{mg}$ ). The new drugs (prasugrel, ticagrelor) are to be administered on admission to the hemodynamic laboratory or after performance of the angiography test prior to the assessment of possible risk of bleeding complications [47].

\section{New generation antiplatelet drugs}

The new drugs cangrelor and elinogrel reversibly inhibit the P2Y12 receptor. These drugs are metabolized in the liver and intestines where active metabolites are formed. They bind to the P2Y12 platelet receptor, reversibly inhibiting platelet activity.

\section{Cangrelor}

Cangrelor is a non-thienopyridine, intravenously administered, reversible $\mathrm{P} 2 \mathrm{Y} 12$ receptor antagonist. The result of platelet inhibition is obtained about $30 \mathrm{~min}$ after the onset of infusion and within an hour of drug discontinuation platelets resume their normal activity [48]. However, some new data have appeared regarding competitive inhibition of the antiplatelet effect of thienopyridine metabolites after the administration of cangrelor. Two studies focusing on cangrelor - CHAMPION-PCI and CHAMPION-PLATFORM - were prematurely discontinued due to the lack of the expected positive results regarding reduction of the primary end-point (death, myocardial infarction, necessity to perform another revascularization due to ischemia within $48 \mathrm{~h}$ ). However, an increased risk of major hemorrhages was observed (3.6\% vs. $2.9 \%$, OR: $1.26 ; 95 \% \mathrm{Cl}: 0.99$ vs. $1.60 ; p=0.06)$. The administration of cangrelor was associated with a decreased risk of stent thrombosis and death within the first $48 \mathrm{~h}$. During the American College of Cardiology Congress in 2013 held in San Francisco, the most up-to-date results of the CHAMPION-PHOENIX study were presented. This is a large, multicenter clinical trial assessing the efficacy of cangrelor in $\mathrm{PCl}$ patients due to both stable CAD and other ACS. The study included 11,145 patients who were randomized for intravenous administration of cangrelor (study group, bolus $30 \mathrm{mg} / \mathrm{kg}+$ infusion $4 \mu \mathrm{g} / \mathrm{kg} / \mathrm{min}$ for 2-4 h) or for oral clopidogrel administration (control group, $300 \mathrm{mg}$ or $600 \mathrm{mg}$ loading dose $+75 \mathrm{mg}$ maintenance dose). The composite primary endpoint was death, myocardial infarction, necessity for revascularization due to ischemia or acute stent thrombosis within $48 \mathrm{~h}$ after $\mathrm{PCl}$. The primary endpoint was observed significantly less frequently in the cangrelor group: $4.7 \%$ vs. $5.9 \%$ ( $p=$ $0.005)$. This result was affected mainly by a smaller number of myocardial infarctions (3.8\% vs. $4.7 \%, p=0.02$ ) and acute stent thrombosis ( $0.8 \%$ vs. $1.4 \%, p=0.005)$. The noted differences were present during a 30-day observation period. A subgroup analysis proved the cangrelor activity result irrespective of $\mathrm{PCl}$ indication. Bleeding incidents were present equally often in the study group and in the control group $(0.16 \%$ vs. $0.11 \%, p=0.44)$ [49]. The positive result of this study will surely pave the way for the development of intravenous P2Y12 receptor antagonists.

\section{Elinogrel}

Elinogrel directly inhibits the $\mathrm{P} 2 \mathrm{Y} 12$ receptor. It reversibly inhibits platelet aggregation and is available both in the oral and intravenous form. So far the performed studies have proved its stronger antiaggregation results as compared to clopidogrel, yet with certain higher inclinations for insignificant hemorrhagic complications. The drug is still undergoing clinical trials. In 2012 the results of the INNOVATE PCI study were published. The main aim of the study was to assess the safety, efficacy and tolerance of elinogrel in patients who underwent elective $\mathrm{PCl}$. The part dealing with pharmacodynamics showed that the patients treated with elinogrel at the doses of $100 \mathrm{mg}$ and $150 \mathrm{mg}$ twice daily showed greater platelet inhibition as compared to the patients treated with clopidogrel, and the patients who received $150 \mathrm{mg}$ presented stronger results of the drug. As for the hemorrhagic complications in patients who intravenously received elinogrel in the dose of $120 \mathrm{mg}$, researchers did not report more frequent major and minor bleedings within $24 \mathrm{~h}$ or before hospital discharge. More bleedings were observed in comparison to clopidogrel in the form of complications at the site of vascular access, which required medical intervention (elinogrel 47/408 (11.5\%) vs. clopidogrel 13/208 (6.3\%)). Moreover, more frequent hemorrhages requiring medical assistance were present within $24 \mathrm{~h}$ to 120 days in patients treated with elinogrel at the dose of $150 \mathrm{mg}$. It needs to be added that the research did not have appropriate statistical properties to assess ischemic endpoints [50]. The implications of these results require further studies in the third stage.

\section{Conclusions}

Antiplatelet drugs play a crucial role in the treatment of patients with myocardial infarction, particularly in association with percutaneous coronary intervention. Their 
main advantage is the reduction of adverse ischemic incidents and the major disadvantage is the increase in the frequency of hemorrhages. Thus, the choice of appropriate drug depends on the right risk assessment of the development of these complications in individual patients.

The most recent studies aimed at introducing new drugs of high efficacy in prevention of ischemic incidents and simultaneously of reversible action raise hopes for better prognosis for myocardial infarction patients.

\section{References}

1. Cook S, Windecker S. Early stent thrombosis: past, present, and future. Circulation 2009; 119: 657-659.

2. Ortolani P, Marzochi A, Marrozzini C, et al. Long-term effectiveness of early administration of glycoprotein $\mathrm{Ilb} / \mathrm{Illa}$ agents to Real-world patients undergoing primary percutaneous interventions: results of a registry study In an ST-elevation myocardial infarction Network. Eur Heart J 2009; 30: 33-43.

3. Huber K, Holmes DR Jr, van 't Hof AW, et al. Use of glycoprotein Ilb/Illa in primary percutaneous coronary intervention: insights from the APEX-AMI trial. Eur Heart J 2010; 31: 1708-1716.

4. De Luca G, Navarese E, Marino P. Risk profile and benefits om Gp Ilb/Illa inhibitors among patients with ST-segment elevation myocardial infarction treated with primary angioplasty: a meta-regression analysis of randomized trials. Eur Heart J 2009; 30 : 2705-2713.

5. Stone GW, Machara A, Witzenbichler B, et al. Intracoronary abciximab and aspiration thrombectomy in patients with large anterior myocardial infarction. JAMA 2012; 307: 1817-1826.

6. Jakubowski JA, Winters KJ, Naganuma H, Wallentin L. Prasugrel: a novel thienopyridine antiplatelet agent. A review of preclinical and clinical studies and the mechanistic basis for its distinct antiplatelet profile. Cardiovasc Drug Rev 2007; 25: 357-374.

7. Anderson JL, Adams CD, Antman EM, et al. ACC/AHA 2007 guidelines for the management of patients with unstable angina/non ST-elevation myocardial infarction. Circulation 2007; 116: 148-304.

8. Trenk D, Hochholzer W, Fromm M. F, et al. Cytochrome P450 2 C19 681G $>$ A polymorphism and high on-clopidogrel platelet reactivity associated with adverse 1-year clinical outcome of elective percutaneous coronary intervention with drug-eluting or bare-metal stents. J Am Coll Cardiol 2008; 51: 1925-1934.

9. CURE Study Investigators. The Clopidogrel in Unstable angina to prevent Recurrent Events (CURE) trial programme: rationale, design and baseline characteristics including a meta-analysis of the effects of thienopyridines in vascular disease. Eur Heart J 2000; 21: 2033-2041.

10. Mehta SR, Yusuf S, Peters RJ, et al. Effects of pretreatment with clopidogrel and aspirin followed by long-term therapy in patients undergoing percutaneous coronary intervention: the PCICURE study. Lancet 2001; 358: 527-533.

11. Chen ZM, Jiang LX, Chen YP, et al. Addition of clopidogrel to aspirin in 45,852 patients with acute myocardial infarction: randomised placebo-controlled trial. Lancet 2005; 366: 1607-1621.

12. Scirica BM, Sabatine MS, Morrow DA, et al. The role of clopidogrel in early and sustained arterial patency after fibrinolysis for ST-segment elevation myocardial infarction: the ECG CLARITY-TIMI 28 study. J Am Coll Cardiol 2006; 48: 37-42.

13. L'Allier PL, Ducrocq G, Pranno N, et al. Clopidogrel 600-mg double loading dose achieves stronger platelet inhibition than con- ventional regimens: results from the PREPAIR randomized study. J Am Coll Cardiol 2008; 51: 1066e72.

14. von Beckerath N, Taubert D, Pogatsa-Murray G, et al. Absorption, metabolization and antiplatelet effects of 300-, 600-, and 900-mg loading doses of clopidogrel: results of the ISAR-CHOICE (Intracoronary Stenting and Antithrombotic Regimen: Choose Between 3 High Oral Doses for Immediate Clopidogrel Effect) Trial. Circulation 2005; 112: 2946-2950.

15. Gurbel PA, Bliden KP, Zaman KA, et al. Clopidogrel loading with eptifibatide to arrest the reactivity of platelets: results of the Clopidogrel Loading With Eptifibatide to Arrest the Reactivity of Platelets (CLEAR PLATELETS) study. Circulation 2005; 111: 1153-1159.

16. Mehta SR, Tanguay JF, Eikelboom JW, et al. Double-dose versus standard-dose clopidogrel and high-dose versus low-dose aspirin in individuals undergoing percutaneous coronary intervention for acute coronary syndromes (CURRENT-OASIS 7): a randomised factorial trial. Lancet 2010; 376: 1233-1243.

17. Bhatt DL, Fox KA, Hacke W, et al. Clopidogrel and aspirin versus aspirin alone for the prevention of atherothrombotic events. N Engl J Med 2006; 354: 1706-1717.

18. Steg PG, James SK, Atar D, et al. ESC Guidelines for the management of acute myocardial infarction in patients presenting with ST-segment elevation: The Task Force on the management of ST-segment elevation acute myocardial infarction of the European Society of Cardiology (ESC). Eur Heart J 2012; 33: 2569-2619.

19. O'Gara PT, Kushner FG, Ascheim DD, et al. 2013 ACCF/AHA Guideline for the Management of ST-Elevation Myocardial Infarction: Foundation/American Heart Association Task Force on Practice Guidelines Executive Summary: a Report of the American College of Cardiology. J Am Coll Cardiol 2013; 61: e78-e140.

20. Mason PJ, Jacobs AK, Freedman JE. Aspirin resistance and atherothrombotic disease. J Am Coll Cardiol 2005; 46: 986-993.

21. Abdel-Latif A, Smyth SS. Preventing platelet thrombosis with a PAR1 pepducin. Circulation 2012; 126: 13-15.

22. Bouman HJ, Schömig E, van Werkum JW, et al. Paraoxonase-1 is a major determinant of clopidogrel efficacy. Nature Medicine 2011; 17: 110-116.

23. Bonello L, Tantry US, Marcucci R, et al. Consensus and future directions on the definition of high on-treatment platelet reactivity to adenosine diphosphate. J Am Coll Cardiol 2010; 56: 919-933.

24. Breet N, Werkum J, Bouman $\mathrm{H}$, et al. Comparison of platelet function tests in predicting clinical outcome in patients undergoing coronary stent implantation. JAMA 2010; 303: 754-762.

25. Sibbing D, Braun S, Morath T, et al. Platelet reactivity after clopidogrel treatment assessed with point-of-care analysis and early drug-eluting stent thrombosis. J Am Coll Cardiol 2009; 53: 849-856.

26. Kurihara A, Hagihara K, Kazui $M$, et al. In vivo metabolizm of antiplatelet agent clopidogrel: cytochrome P450 isoforms responsible for two oxidation steps involved in active metabolite formation. Drug Dev Rev 2005; 37 (Suppl. 2): 99.

27. Shuldiner AR, O'Connell JR, Bliden KP, et al. Association of cytochrome P450 2C19 genotype with the antiplatelet effect and clinical efficacy of clopidogrel therapy. J Am Med Assoc 2009; 302: 849-857.

28. Gurbel PA, Tantry US. Platelet function testing and genotyping improve outcome in patients treated with antithrombotic agents. Circulation 2012; 125: 1276-1287.

29. Hulot JS, Collet JP, Silvain J, et al. Cardiovascular risk in clopidogrel-treated patients according to cytochrome $\mathrm{P} 4502 \mathrm{C} 19^{\star} 2$ loss- 
of-function allele or proton pump inhibitor coadministration: a systematic meta-analysis. J Am Coll Cardiol 2010; 56: 134-143.

30. Tantry US, Bliden KP, Wei C, et al. First analysis of the relation between cyp2c19 genotype and pharmacodynamics in patients treated with ticagrelor versus clopidogrel: the onset/offset and respond genotype studies. Circ Cardiovasc Genet 2010; 3: 556-566.

31. Mega JL, Close SL, Wiviott SD, et al. Cytochrome p450 genetic polymorphisms and the response to prasugrel: relationship to pharmacokinetic, pharmacodynamic, and clinical outcomes. Circulation 2009; 119: 2553-2560.

32. Jeong YH, Tantry US, Kim IS, et al. Effect of CYP2C19*2 and *3 loss-of-function alleles on platelet reactivity and adverse clinical events in East Asian acute myocardial infarction survivors treated with clopidogrel and aspirin. Circ Cardiovasc Interv 2011; 4: 585-594.

33. Krishna V, Diamond G, Kaul S. The role of platelet reactivity and genotype testing in the prevention of atherothrombotic cardiovascular events remains unproven. Circulation 2012; 125: 12881303.

34. Pare G, Mehta SR, Yusuf S, et al. Effects of CYP2C19 genotype on outcomes of clopidogrel treatment. N Engl J Med 2010; 363: 1704-1714.

35. Holmes M, Perel P, Shah T, et al. CYP2C19 genotype, clopidogrel metabolism, platelet function and cardiovascular events. A systemic review and meta-analysis. JAMA 2011; 306: 2704-2714.

36. Bouman HJ, Schömig E, van Werkum JW, et al. Paraoxonase-1 is a major determinant of clopidogrel efficacy. Nature Medicine 2011; 17: 110-116.

37. Gong IY, Crown N, Suen C. M, et al. Clarifying the importance of CYP2C19 and PON1 in the mechanism of clopidogrel bioactivation and in vivo antiplatelet response. Eur Heart J 2012; 33: 2856-2464.

38. Montalescot G, Wiviott S, Braunwald E, et al. For the TRITON-TIMI 38 investigators Prasugrel compared with clopidogrel in patients undergoing percutaneous coronary intervention for ST-elevation myocardial infarction (TRITON-TIMI 38): double-blind, randomised controlled trial. Lancet 2009; 373: 723-731.

39. Roe MT, Armstrong PW, Fox KA, et al. Prasugrel versus clopidogrel for acute coronary syndromes without revascularization. N Engl J Med 2012; 367: 1297-1309.

40. Diodati J, Fung A, Saucedo J, et al. Transferring from clopidogrel loading dose to prasugrel loading dose in acute coronary syndrome patients: the triplet trial. Can J Cardiol 2012; 28: 377.

41. Cannon CP, Husted S, Harrington RA, et al. Safety, tolerability, and initial efficacy of AZD6140, the first reversible oral adenosine diphosphate receptor antagonist, compared with clopidogrel, in patients with non-ST-segment elevation acute coronary syndrome: primary results of the DISPERSE-2 trial. J Am Coll Cardiol 2007; 50: 1844-1851.

42. Gurbel PA, Bliden KP, Butler K, et al. Randomized double-blind assessment of the ONSET and OFFSET of the antiplatelet effects of ticagrelor versus clopidogrel in patients with stable coronary artery disease. The ONSET/OFFSET study. Circulation 2009; 120: 2577-2585.

43. Van't Hoft AWJ. Early and aggresive treatment of patients with ST-segment elevation myocardial infarction: deciphering recent clinical trials and the timing of optimal platelet inhibition. Eur Heart J 2010; 19 (Supl. D): D24-D35.

44. Quinlan DJ, Eikelboom JW, Goodman SG, et al. Implications of variability in definition and reporting of major bleeding in ran- domized trials of oral P2Y 12 inhibitors for acute coronary syndromes. Eur Heart J 2011; 32: 2256-2265.

45. James SK, Storey RF, Khurmi NS, et al. Ticagrelor versus Clopidogrel in patients with acute coronary syndromes and a history of stroke or transient ischemic attack. Circulation 2012; 125: 2914-2921.

46. Cannon CP, Harrington RA, James S, et al. Comparison of ticagrelor with clopidogrel in patients with a planned invasive strategy for acute coronary syndrome (PLATO): a randomised double-blind stydy. Lancet 2012; 375: 283-293.

47. Dudek D, Filipiak K, Stępińska J, et al. Nowy model optymalnego doustnego leczenia przeciwpłytkowego pacjentów z zawałem serca z uniesieniem odcinka ST w Polsce. Stanowisko Polskiego Towarzystwa kardiologicznego. Kardiol Pol 2011; 69: 986-994.

48. Dovlatova NL, Jakubowski JA, Sugidachi A, Heptinstall S. The reversible P2Y antagonist cangrelor influences the ability of the active metabolites of clopidogrel and prasugrel to produce irreversible inhibition of platelet function. J Thromb Haemost 2008; 6: 1153-1159.

49. Bhatt D, Stone G, Mahaffey K, et al. Effect of platelet inhibition with Cangrelor during $\mathrm{PCl}$ on ischemic events. N Engl I Med 2013; 368: 1303-1313.

50. Welsh RC, Rao SV, Zeymer U, et al. A randomized, double-blind, active-controlled phase 2 trial to evaluate a novel selective and reversible intravenous and oral $\mathrm{P} 2 \mathrm{Y} 12$ inhibitor elinogrel versus clopidogrel in patients undergoing nonurgent percutaneous coronary intervention: the INNOVATE-PCI trial. Circ Cardiovasc Interv 2012; 5: 336-346. 